\title{
The potassium channel KCa3.1 constitutes a pharmacological target for astrogliosis associated with ischemia stroke
}

Mengni Yi ${ }^{1}$, Tianjiao Wei ${ }^{1}$, Yanxia Wang ${ }^{2}$, Qin Lu', Gaoxian Chen ${ }^{1}$, Xiaoling Gao ${ }^{1}$, Herbert M. Geller ${ }^{3^{*}}$, Hongzhuan Chen ${ }^{1 *}$ and Zhihua $Y u^{1 *}$

\begin{abstract}
Background: Reactive astrogliosis is one of the significantly pathological features in ischemic stroke accompanied with changes in gene expression, morphology, and proliferation. KCa3.1 was involved in TGF- $\beta$ induced astrogliosis in vitro and also contributed to astrogliosis-mediated neuroinflammation in neurodegeneration disease.

Methods: Wild type mice and $\mathrm{KCa} 3.1^{-/-}$mice were subjected to permanent middle cerebral artery occlusion (pMCAO) to evaluate the infarct areas by 2,3,5-triphenyltetrazolium hydrochloride staining and neurological deficit. KCa3.1 channels expression and cell localization in the brain of pMCAO mice model were measured by immunoblotting and immunostaining. Glia activation and neuron loss was measured by immunostaining. DiBAC4 (3) and Fluo-4AM were used to measure membrane potential and cytosolic $\mathrm{Ca}^{2+}$ level in oxygenglucose deprivation induced reactive astrocytes in vitro.

Results: Immunohistochemistry on pMCAO mice infarcts showed strong upregulation of KCa3.1 immunoreactivity in reactive astrogliosis. $\mathrm{KCa} 3.1^{-/-}$mice exhibited significantly smaller infarct areas on PMCAO and improved neurological deficit. Both activated gliosis and neuronal loss were attenuated in $\mathrm{KCa} 3.1^{-1-}$ pMCAO mice. In the primary cultured astrocytes, the expressions of KCa3.1 and TRPV4 were increased associated with upregulation of astrogliosis marker GFAP induced by oxygen-glucose deprivation. The activation of KCa3.1 hyperpolarized membrane potential and, by promoting the driving force for calcium, induced calcium entry through TRPV4, a cation channel of the transient receptor potential family. Double-labeled staining showed that KCa3.1 and TRPV4 channels co-localized in astrocytes. Blockade of KCa3.1 or TRPV4 inhibited the phenotype switch of reactive astrogliosis.
\end{abstract}

Conclusions: Our data suggested that KCa3.1 inhibition might represent a promising therapeutic strategy for ischemia stroke.

Keywords: Astrocytes, Mouse, GFAP, Ischemia, Calcium

\footnotetext{
* Correspondence: geller@helix.nih.gov; hongzhuan_chen@hotmail.com; yuzhihua@shsmu.edu.cn

${ }^{3}$ Developmental Neurobiology Section, Division of Intramural Research, National Heart, Lung, and Blood Institute, National Institutes of Health, Bethesda, MD 20892, USA

${ }^{1}$ Department of Pharmacology, Institute of Medical Sciences, Shanghai Jiao

Tong University School of Medicine, Shanghai 200025, China

Full list of author information is available at the end of the article
} 


\section{Background}

During pathological brain insults such as cerebral ischemia, a rapid increase of intracellular calcium initiates apoptotic and necrotic cell death and reactive gliosis. Several lines of evidence suggest that $\left[\mathrm{Ca}^{2+}\right]_{\mathrm{i}}$ oscillations evoked by focal ischemia spread through the astrocytes and cause damage in distal regions of the central nervous system (CNS) [1]. KCa3.1, a $\mathrm{Ca}^{2+}$-activated potassium channel, is involved in regulating membrane potential during activation of non-excitable inflammatory and structural cells, including astrocytes, in response to $\mathrm{Ca}^{2+}$ influx [2-4]. As such, $\mathrm{KCa} 3.1$ is a promising target to ameliorate the phenotype switch of astrocytes and microglia from resting to astrogliosis and microglia activation in ischemia, traumatic brain injury, Alzheimer's disease (AD) as well as spinal cord injury $[5,6]$.

Most recently, we reported that $\mathrm{KCa} 3.1$ was increased in reactive astrocytes as well as neurons in the brains of both mouse models of $\mathrm{AD}$ and $\mathrm{AD}$ patients. Furthermore, the blockade of $\mathrm{KCa} 3.1$ resulted in a decrease in astrogliosis and an attenuation of memory deficits in the AD mouse model [7]. After ischemic stroke in rats, blood-brain barrier endothelial cells exhibited $\mathrm{KCa} 3.1$ protein and activity, and pharmacological blockade of KCa3.1 significantly reduced $\mathrm{Na}^{+}$uptake and cytotoxic edema [8]. Moreover, in a mouse model of ischemia, genetic deletion and wild type mice treated with the KCa3.1 blocker TRAM-34 resulted in a decrease in infarct areas and improved neurological deficits [9]. These findings suggest that $\mathrm{KCa} 3.1$ channels are important in the process of stroke, and that their blockade might prove useful as therapy in stroke with upregulated $\mathrm{KCa} 3.1$ expression.

Over the past few years, a large number of studies suggested that astroglial calcium influx after ischemia could be mediated by the activation of $\mathrm{Ca}^{2+}$ permeable cation channels such as transient receptor potential (TRP) channels. The transient receptor potential vanilloid 4 (TRPV4) channel is widely expressed in the CNS, with demonstrated function not only in neurons and astrocytes but also in endothelial cells of cerebral arteries [10]. During cerebral ischemia, TRPV4 was overactivated by cytotoxic edema or the metabolites of arachidonic acid (AA), and TRPV4-mediated $\mathrm{Ca}^{2+}$ entry likely played a role in the intracellular $\mathrm{Ca}^{2+}$ overload [11]. Blockade of the TRPV4 channel reduced the damage to hippocampal pyramidal neurons and astrocytes upon oxidative stress [12] or oxygen-glucose deprivation [13] in vitro and reduced brain infarction in a mouse model of focal cerebral ischemia [14]. At present, the signal transduction pathways used by TRPV4 to induce astrogliosis are not well defined but seem mostly related to calcium overload of the cells, as TRPV4 channels are involved in ischemia-induced calcium entry in reactive astrocytes and thus, might participate in the pathogenic mechanisms of astroglial reactivity following ischemic insult [15].

The present study aims to investigate the mechanisms by which $\mathrm{KCa} 3.1$ regulates $\mathrm{Ca}^{2+}$ entry via TRPV4 channels, leading to reactive astrogliosis during ischemia stroke. We show, for the first time, a potential colocalization between $\mathrm{KCa} 3.1$ and TRPV4 channels in astrocytes. This co-localization allows $\mathrm{KCa} 3.1$ to maintain a negative membrane potential during astrogliosis, thus increasing the driving membrane potential for $\mathrm{Ca}^{2+}$ influx through TRPV4 channels. These strongly suggest that $\mathrm{KCa} 3.1$ is involved in reactive astrogliosis in the process of stroke, making it a promising target for the development of novel therapies.

\section{Methods}

Permanent focal cerebral ischemia

The study (ethics protocol number: A-2015-010) was approved by the Animal Care and Use Committee of the Shanghai Jiao Tong University School of Medicine, Shanghai, China. KCa3.1 $1^{-/-}$mice were obtained from the Jackson Laboratory as described precisely [16-18]. 10-12 week old male C57BL/6 wild type mice and $\mathrm{KCa} 3.1^{-/-}$mice were housed in a specific pathogen-free animal facility. A permanent focal cerebral ischemia model was prepared in accordance with the guidelines as described previously [19]. In brief, adult male mice weighing 23 to $27 \mathrm{~g}$ were anesthetized with $2 \%$ chloral hydrate and body temperature was maintained at $37 \pm 0.5^{\circ} \mathrm{C}$ throughout the surgery using a heating pad and lamp (ALC-HTP, Shanghai Alcott Biotech Co. Ltd). To induce permanent focal cerebral ischemia, a silicon rubbed-counted suture with a tip diameter of $0.22 \mathrm{~mm}$ (L2000, AAA, Guangzhou Jialing Biiotech Co, Ltd.) was inserted into the left external carotid artery to block the middle cerebral artery. Transcranial laser Doppler (moorVMS-LDF2) was used to monitor cerebral blood flow $(\mathrm{CBF})$ to assure reduction of $\mathrm{CBF}$ through the surgery (Additional file 1: Figure S1). The sham-operated mice experienced the same surgical operations except for the silicon rubbed-counted suture inserted.

\section{Stroke study population and quality control}

The operators were not involved in data analysis and acquisition. The observers performed the surgeries, and parameters evaluation was unaware of the group to which each mouse belonged. The following conditions excluded mice from end-point analyses (exclusion criteria): (1) < $80 \%$ reduction in CBF; (2) subarachnoid hemorrhage or the brain parenchyma bleeding (as macroscopically assessed during brain sampling); (3) neurological score $=0$ ( $6 \mathrm{~h}, 24 \mathrm{~h}$ after pMCAO); and (4) operation time $>10 \mathrm{~min}$. In total, 158 mice (86 C57BL/6 WT, $72 \mathrm{KCa} 3.1^{-/-}$) were 
used in this study. Of the 120 mice subjected to pMCAO, 12 mice $(10 \%)$ met at least one exclusion criterion after randomization and, therefore, were withdrawn from the study.

\section{Measurement of neurological deficits}

Mice were studied for neurological deficits at 3, 6, and $24 \mathrm{~h}$ after pMCAO as described previously [20]. Briefly, neurological findings were scored on a 5-point scale: 0 , no observable neurological deficits (normal); (1) failure to extend the right forepaw (mild); (2) circling to the contralateral side (moderate); (3) loss of walking or righting reflex (severe); (4) dead. The observers were unaware of the group to which each mouse belonged.

\section{Determination of infarct volume}

Groups of mice were euthanized at 3, 6, and $24 \mathrm{~h}$ after MCAO. Brains were quickly removed and chilled at $-20^{\circ}$ $\mathrm{C}$ for $20 \mathrm{~min}$ to slightly harden the tissue. Then brains were sectioned into five $1 \mathrm{~mm}$-thick coronal slices starting from the frontal pole. All sections were stained with $2 \%$ 2,3,5-triphenyltetrazolium hydrochloride in the dark for $20 \mathrm{~min}$ at $37^{\circ} \mathrm{C}$ and flipped every $5 \mathrm{~min}$ for staining of anterior and posterior faces [21]. Finally slices were fixed in $4 \%$ paraformaldehyde overnight at $4{ }^{\circ} \mathrm{C}$. ImageJ was used to measure the infarct area of each brain.

\section{Immunohistochemistry}

For immunofluorescence staining of serial brain coronal sections $(12 \mu \mathrm{m})$ and cultured cells, the tissues and cells were blocked with $1 \%$ bovine serum albumin and $1 \%$ goat normal serum $1 \mathrm{~h}$ at room temperature. Sections and cells were incubated at $4{ }^{\circ} \mathrm{C}$ overnight with primary antibodies: mouse anti-KCa3.1 (1:100; Alomone Labs), rabbit antiGFAP (1:500; Dako); rabbit anti-Iba1 (1:500; Abcam); rabbit anti-NeuN antibody (1:500; Millipore), rabbit antiTRPV4 (1:200; Alomone Labs). The sections and cells were incubated with following secondary antibodies: Alexa Fluor 555 goat anti-rabbit IgG (1:500; Invitrogen), Alexa Fluor 488 goat anti-mouse IgG (1:500; Invitrogen) for $1 \mathrm{~h}$ at room temperature. Then washed with PBS and stained with DAPI (4', 6-diamidino-2-phenylindole).

\section{Data collection and statistics of immunofluorescence}

Twelve-micrometer-thick brain slices were collected from mice and four slices at $120 \mu \mathrm{m}$ intervals from each brain were used to examine GFAP, Iba-1, and NeuN positive cells.

The average optical density of GFAP. At least three microscopic photographs of vision were selected in hippocampus or cortex of each immunofluorescence hemisphere slice. Leica.TCS.SP8 Laser scanning confocal microscope was used to capture photographs, which were obtained under the same confocal settings. The area of the AOI (area of interest, area) and the integral optical density (IOD) value was measured using the Image-Pro Plus 6.0 software as in previous study [22], and the IOD/ area was calculated to obtain the mean IOD in each image. At last, the final mean IOD of each slice was determined by the average of the mean IOD in each image.

Cell counting. At least three fields were captured in each slice with the same reference position for quantification. The numbers of $\mathrm{Iba}^{+}$and $\mathrm{NeuN}^{+}$cells per $1 \mathrm{~mm}^{2}$ in each slice were counted using the Image-Pro Plus 6.0 software. The data from at least three photographs of each hemisphere slice were averaged as one value and values from three slices were calculated.

Analysis of co-localization. For analysis of TRPV4 and $\mathrm{KCa} 3.1$ co-localization, images were processed and analyzed using Leica LAS AF Lite software (Leica, Germany). Pearson correlation was used to express the degree of co-localization as described early [23, 24]. The co-localization of KCa3.1 and TRPV4 in the overlap of the two channels was assessed using the co-localization tool in Leica LAS AF Lite software. The Pearson correlation values range from -1 to +1 . A correlation of 1 indicates complete co-localization between the two proteins. A correlation of -1 indicates a negative interaction, and a correlation of 0 indicates no co-localization between the two proteins [24].

\section{Primary culture of astrocytes}

Primary astrocyte cultures were prepared from neonatal (0-2 days old) C57BL/6 wild type or $\mathrm{KCa} 3.1^{-1-}$ mouse brains as described previously [17]. Briefly, the cerebral cortices were dissected out and dissociated into a single cell suspension. When cells grew to confluence (10-14 days later), flasks were shaken overnight $\left(200 \mathrm{rpm}, 37^{\circ} \mathrm{C}\right)$ and the medium exchanged to remove adherent microglia and oligodendrocytes. The purified astrocytes were plated into plates in serum-containing DMEM. After once again reaching confluence, the medium was exchanged for serum-free DMEM for $24 \mathrm{~h}$ before treatments. In some cases, the cells were pretreated with the blockers $30 \mathrm{~min}$ before oxygen-glucose deprivation.

\section{Oxygen-glucose deprivation and drug exposure}

Confluent astrocytes were grown in serum-free DMEM for $24 \mathrm{~h}$ before OGD, at which time the culture medium was replaced with glucose/glutamine-free DMEM medium after a gentle cell washing with the same medium. The serumfree and glucose/glutamine-free DMEM medium was balanced for 30 min with $95 \%(v / v) \mathrm{N}_{2}, 5 \%(v / v) \mathrm{CO}_{2}$ at $37^{\circ} \mathrm{C}$ before OGD. Then cells were exposed to hypoxia for different time points in a small anaerobic chamber filled with 95\% $(v / v) \mathrm{N}_{2}$ and $5 \%(v / v) \mathrm{CO}_{2}$ at $37{ }^{\circ} \mathrm{C}$. Drugs and inhibitors were pretreated to the cells $30 \mathrm{~min}$ before OGD. A Cell 
Counting Kit-8 (CCK-8, Dojindo Laboratories, Kumamoto, Japan) was used to measure cell viability [25].

\section{Western blotting}

Mouse brain tissues or astrocytes were homogenized in RIPA buffer (25 mM Tris pH 7.4, $150 \mathrm{mM} \mathrm{NaCl,} \mathrm{1 \%}$ NP-40) containing $0.1 \%$ sodium dodecyl sulfate (SDS) and $4 \%$ protease inhibitor (complete protease inhibitor cocktail, Roche). Tissue lysates were centrifuged at $13500 \mathrm{rpm}$ for $30 \mathrm{~min}$ at $4{ }^{\circ} \mathrm{C}$, and supernatants were collected. Total lysates were diluted in $2 \times$ SDS sample buffer (120 mM Tris/HCl, 10\% SDS, 20\% glycerine, 20\% 2-mercaptoethanol, $\mathrm{pH}$ 6.8) to a final concentration of $2 \mu \mathrm{g} / \mu \mathrm{l}$ and were used for western blotting. The following primary antibodies were used: anti-KCa3.1 (1:500; Abcam), anti-TRPV4 (1:500; Alomone Labs), anti-GFAP (1:2000; Z0334, Dako), and anti- $\beta$-actin (1:1000; Santa Cruz). HRP-conjugated anti-rabbit or anti-mouse IgG secondary antibodies (1:3000; Amersham Biosciences) were used for $1 \mathrm{~h}$ at room temperature. ImageJ software was used to quantify the protein bands and normalized to the actin band, which served as loading control [26].

\section{Cell viability}

Cell viability was assessed using a Cell Counting Kit-8 (CCK-8, Dojindo Molecular Technologies) as previously described [4]. Briefly, the confluent astrocytes were cultured in serum-free media for $24 \mathrm{~h}$ and were then treated with OGD for different time points $(1,3,46$, $12 \mathrm{~h}$ ). Ten microliter CCK-8 was added to each well of the 96-well plate and then was placed in a $\mathrm{CO}_{2}$ incubator for $2 \mathrm{~h}$. Measure the absorbance at $450 \mathrm{~nm}$ with a microplate reader.

\section{Membrane potential measurement}

Bis-(1,3-dibutylbarbituric acid) trimethine oxonol [DiBAC4(3)], the potentiometric fluorescent dye, was used to measure membrane potential as described previously [27]. Briefly, primary cultured astrocytes were loaded with $100 \mathrm{nmol} / \mathrm{l}$ DiBAC4 (3) for $20 \mathrm{~min}$ to ensure dye distribution across the cell membrane at $37^{\circ} \mathrm{C}$ in an incubator. 1-EBIO $(200 \mu \mathrm{M})$ or $\operatorname{RN} 1747(10 \mu \mathrm{M})$ was added to the cells at 60 s. A TCS SP8 confocal laserscanning microscope (Leica, Germany) was used to evaluate relative changes in membrane potential by monitoring DiBAC4(3) fluorescence. TRAM-34 (1 and $10 \mu \mathrm{M})$ or $\mathrm{HC} 067047(10 \mu \mathrm{M})$ was added $1 \mathrm{~h}$ before the experiment. DiBAC4(3) fluorescence was measured at $530 \mathrm{~nm}$ with excitation at $488 \mathrm{~nm}$. Confocal images were taken and stored every $1 \mathrm{~s}$ for $1800 \mathrm{~s}$.

\section{$\left[\mathrm{Ca}^{2+}\right]_{\mathrm{i}}$ measurement}

Cytosolic $\mathrm{Ca}^{2+}\left(\left[\mathrm{Ca}^{2+}\right]_{\mathrm{i}}\right)$ was measured as described previously [27]. Briefly, astrocytes were loaded with $5 \mu \mathrm{M}$
Fluo-4 AM (MAIBIO, Shanghai, China) for $30 \mathrm{~min}$ at $37{ }^{\circ} \mathrm{C}$ in an incubator, rinsed, and incubated in DMEM with the appropriate test reagents. Baseline fluorescence was measured for the first $60 \mathrm{~s}$, and then 1-EBIO (200 $\mu \mathrm{M})$ or RN1747 $(10 \mu \mathrm{M})$ was added to the cell plate. A TCS SP8 confocal laser-scanning microscope (Leica, Germany) was used to evaluate relative changes in intracellular calcium concentration $\left(\left[\mathrm{Ca}^{2+}\right]_{\mathrm{i}}\right)$ by monitoring Fluo-4 fluorescence. TRAM-34 (1 and $10 \mu \mathrm{M})$ or $\mathrm{HC}$ $067047(10 \mu \mathrm{M})$ was added $1 \mathrm{~h}$ before the experiment. Fluo-4 fluorescence was measured at $510 \mathrm{~nm}$, with excitation at $488 \mathrm{~nm}$. Confocal images were taken and stored every $1 \mathrm{~s}$ for $360 \mathrm{~s}$.

\section{Statistical analysis}

All data are presented as means \pm SEM. Statistical analyses were performed using Prism software (GraphPad Software, Inc., La Jolla, CA, USA). Data were tested for Gaussian distribution with the Kolmogorov-Smirnov normality test and then analyzed by one-way ANOVA and Dunnett's post hoc tests. Data were analyzed with unpaired, two-tailed Student's $t$ test when comparing between two groups, or the non-parametric Mann-Whitney test was applied. Statistical significance was set at $p<0.05$.

\section{Results \\ Upregulation of KCa3.1 expression in the brains of pMCAO mice}

Most recently, we reported $\mathrm{KCa} 3.1$ was increased in reactive astrocytes in the brains of both mouse models of $\mathrm{AD}$ and $\mathrm{AD}$ patients, and pharmacological inhibition or genetic deletion of $\mathrm{KCa} 3.1$ reduced astrogliosis-induced neuronal loss in the AD mouse model [7]. Based on this, we hypothesized that $\mathrm{KCa} 3.1$ is also mechanistically involved in astrogliosis-mediated neuronal damage following ischemic stroke. Here, we chose a mouse model of pMCAO as described previously [19]. Following MCAO blockage, the expression of both $\mathrm{KCa} 3.1$ and GFAP was significantly increased in the infarcted hemisphere of pMCAO mice as detected by western blotting (Fig. 1a, b) for up to $12 \mathrm{~h}$ (Additional file 2: Figure S2).

Co-immunostaining of $\mathrm{KCa} 3.1$ with specific for neurons, astrocytes, and microglia was performed on brain sections of control and $6 \mathrm{~h}$ pMCAO mice. KCa3.1 expression was found in $\mathrm{NeuN}^{+}$neurons in the brains of both control and $6 \mathrm{~h}$ pMCAO mice (Fig. 1c). Less KCa3.1 expression was detected in the neurons of pMCAO mice because of the cells loss during the pathology process of ischemia compared to the control group, but there was no obviously difference in the percentage of the co-localization between pMCAO and control group. In control mice, a low level of expression of $\mathrm{KCa} 3.1$ was detected in $\mathrm{GFAP}^{+}$astrocytes (Fig. 1d). However, at $6 \mathrm{~h}$ pMCAO, we detected a clear co-localization between $\mathrm{KCa} 3.1$ and $\mathrm{GFAP}^{+}$reactive 


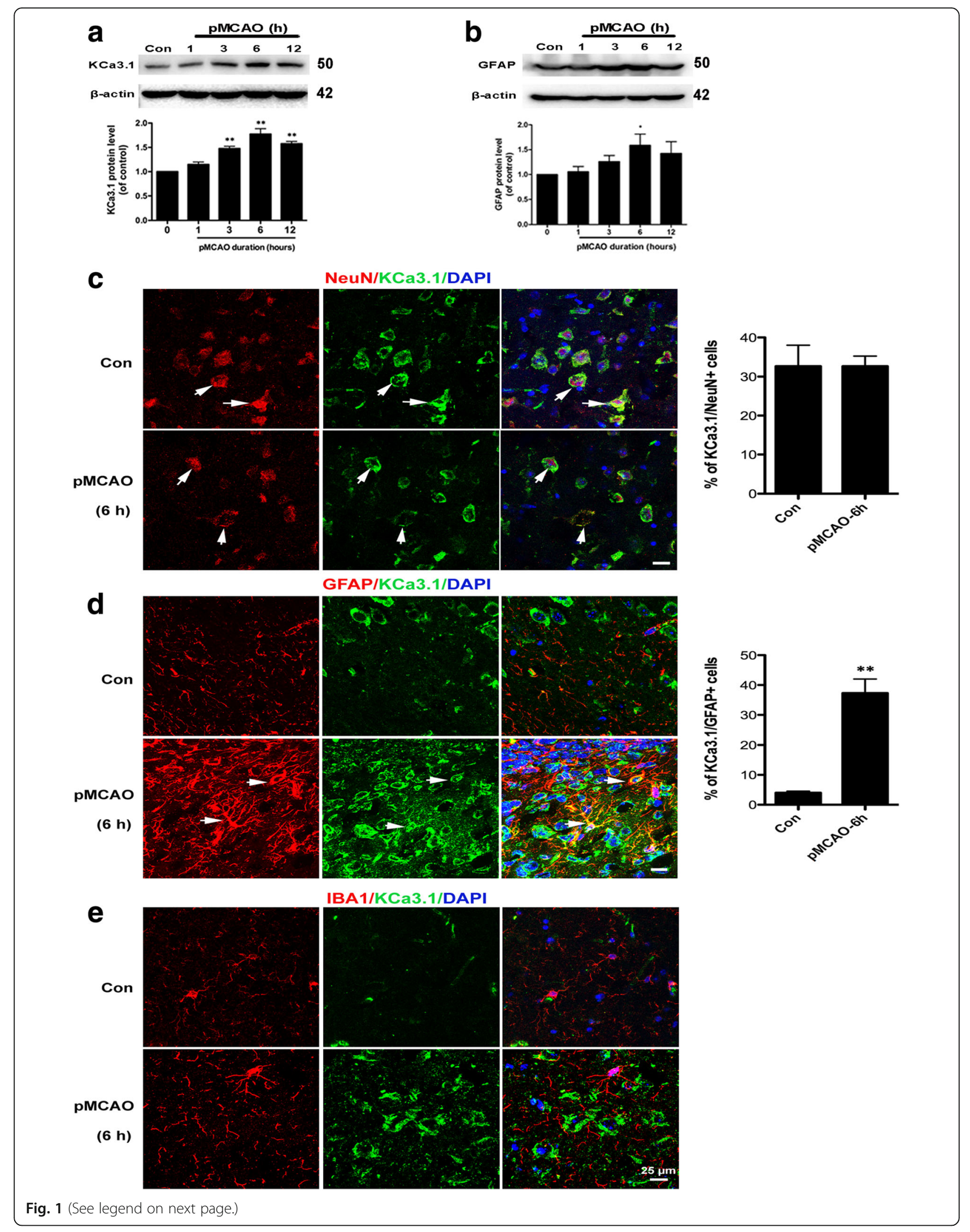


(See figure on previous page.)

Fig. 1 Upregulation of KCa3.1 channels and GFAP in mouse brains following PMCAO. a, b Western blot analysis of lysates from 10-week-old male WT mice following $1,3,6$, or 12 h of pMCAO analyzed by antibodies to KCa3.1 (a) and GFAP (b). Data represent the means \pm SEM of KCa3.1 and GFAP density normalized to $\beta$-actin values for $n=3 .{ }^{*} p<0.05,{ }^{* *} p<0.01$, one-way ANOVA followed by the Dunnett's multiple comparison test compared with control. Con control. c-e Cellular localization of KCa3.1 channels in mouse brains following pMCAO. Double immunofluorescence analysis of KCa3.1 (green) levels in (c) neurons (NeuN, red), (d) astrocytes (GFAP, red), and (e) microglia (lba1, red) of control and $6 \mathrm{~h}$ pMCAO mouse brain. DAPI (blue) was used to label nuclei. Quantification of the percentage of $\mathrm{NeuN}^{+}$(c) or $\mathrm{GFAP}^{+}$(d) cells colabeled for KCa3.1 at 6 h pMCAO compared with the control group. ${ }^{* *} p<0.01$, unpaired, two-tailed Student's $t$ test compared with control mice $(n=4)$. Scale bar: $25 \mu m$. Con control

astrocytes in the infarct regions $(p<0.01$, Fig. 1d), which is consistent with our previous reports in AD [7]. Because Chen et al. [9] reported acutely isolated microglia from the brains of transient MCAO mice with 8 days of reperfusion exhibit increased function of KCa3.1 channels, so we labeled sections from the $6 \mathrm{~h}$ pMCAO for KCa3.1 and the microglial marker Iba1. There was no obvious colocalization between $\mathrm{KCa} 3.1$ and microglia at $6 \mathrm{~h}$ pMCAO (Fig. 1e).

\section{Genetic KCa3.1 deletion reduces infarct area and improve neurological deficit in PMCAO}

In order to study the role of KCa3.1 deficiency on the pathological processes of ischemic stroke, we subjected wild type (WT) and $\mathrm{KCa} 3.1$ gene deletion $\left(\mathrm{KCa} 3.1^{-1-}\right.$ ) mice to 3, 6, and $24 \mathrm{~h}$ of pMCAO and assessed infarct volumes and neurological deficits (Fig. 2). As shown in Fig. $2 \mathrm{a}-\mathrm{f}$, the infarct area measurements by TTC staining in pMCAO brains indicated that infarct volumes in $\mathrm{KCa} 3.1^{-/-}$mice was smaller than those in WT mice, and infarct areas in $\mathrm{KCa} 3.1^{-/}$mice were significantly reduced by $19 \%$ at $6 \mathrm{~h}$ after pMCAO compared with those in WT mice ( $p<0.05$, Fig. $2 \mathrm{c}, \mathrm{d})$ but there was no significant difference in infarct measurement at $3 \mathrm{~h}$ $(p=0.3085$, Fig. 2a, b) and $24 \mathrm{~h}$ after stroke $(p=0.0951$, Fig. 2e, f). Furthermore, the neurological deficit scores of $\mathrm{KCa} 3.1^{-1-}$ mice were significantly lower than those of WT mice at $24 \mathrm{~h}$ after pMCAO $(p<0.05$, Fig. $2 \mathrm{~g})$. The survival rate of $24 \mathrm{~h}$ after pMCAO was significantly higher in $\mathrm{KCa} 3.1^{-1-}$ mice than that in WT mice $(p<0.05,66.7 \%(12 / 18)$ vs $37.5 \%$ (6/16), Fig. $2 \mathrm{~g})$.

\section{Genetic KCa3.1 deficiency reduces neuron loss and gliosis induced by PMCAO}

It is well documented that reactive gliosis of both astrocytes and microglia are two hallmark features of ischemia and its penumbral region [28]. We previously showed in primary astrocyte cultures and an $\mathrm{AD}$ mouse model that inhibition of $\mathrm{KCa} 3.1$ attenuated the reactive glial response [7]. Furthermore, we also demonstrated that deletion or inhibition of KCa3.1 reduced astrogliosis-induced neurotoxicity in a co-culture system of neurons-astrocytes [7]. To assess the role of $\mathrm{KCa} 3.1$ in the process of ischemic stroke, neuron survival and glial activation were measured by immunostaining with markers of neurons, astrocyte, and microglia in WT and $\mathrm{KCa} 31^{-/-}$mice $6 \mathrm{~h}$ after pMCAO. Significantly fewer $\mathrm{GFAP}^{+}$astrocytes $(p<0.05$, Fig. $3 \mathrm{a})$ and $\mathrm{Iba} 1^{+}$microglia $(p<0.01$, Fig. $3 \mathrm{~b})$ were detected in the $6 \mathrm{~h}$ pMCAO brains of $\mathrm{KCa} 3.1^{-1-}$ mice as compared to WT mice, while more $\mathrm{NeuN}^{+}$neurons were detected in the $6 \mathrm{~h}$ pMCAO brains of $\mathrm{KCa} 3.1^{-1-}$ mice as compared to WT mice $(p<0.01$, Fig. $3 c)$. As shown in Fig. 3d, the images of Fig. 3a-c were taken from CA1 (Additional file 3: Figure S3). Overall, these results suggest that targeted deletion of $\mathrm{KCa} 3.1$ has neuroprotective effects against cerebral ischemic injury induced by pMCAO.

\section{KCa3.1 and TRPV4 mediate oxygen-glucose deprivation induced astrogliosis}

We previously found in primary astrocyte cultures that KCa3.1 expression was increased in reactive astrocytes induced by TGF- $\beta$, while pharmacological blockade or genetic deletion of $\mathrm{KCa} 3.1$ attenuated astrogliosis [17]. Butenko et al. [15] reported that TRPV4 was markedly enhanced in astrocytes of the CA1 region after hypoxia/ ischemia and that increased TRPV4 expression coincided with the development of astrogliosis. We therefore investigated the hypothesis that $\mathrm{KCa} 3.1$ regulates $\mathrm{Ca}^{2+}$ entry via the TRPV4 channel leading to reactive astrogliosis-induced neuronal damage during ischemia stroke. We firstly evaluated the expression of $\mathrm{KCa} 3.1$ and TRPV4 during the process of OGD-induced astrogliosis in vitro. Primary cultured astrocytes were subject to OGD for $1,3,4,6$, or $12 \mathrm{~h}$ to induce reactive astrogliosis as described previously [29]. As shown in Fig. 4, OGD induced a time-dependent upregulation of $\mathrm{KCa} 3.1$ and TRPV4 channels, which was consistent with the upregulation of GFAP (Fig. 4a-c). The cell viability analysis showed a significant decrease in astrocytes viability during 1-12 $\mathrm{h}$ after OGD treatment (Fig. 4d). These data suggested that the increase in KCa3.1 and TRPV4 occurred concomitantly with upregulation of GFAP during the process of OGD-induced reactive astrogliosis.

\section{KCa3.1 channels hyperpolarize reactive astrocytes} membrane potential during oxygen-glucose deprivation To further establish the relationship between $\mathrm{KCa} 3.1$ and TRPV4 in regulating reactive astrocytes during ischemia stroke, we investigated the role of TRPV4 in the process of $\mathrm{KCa} 3.1$ regulated membrane potential. As 

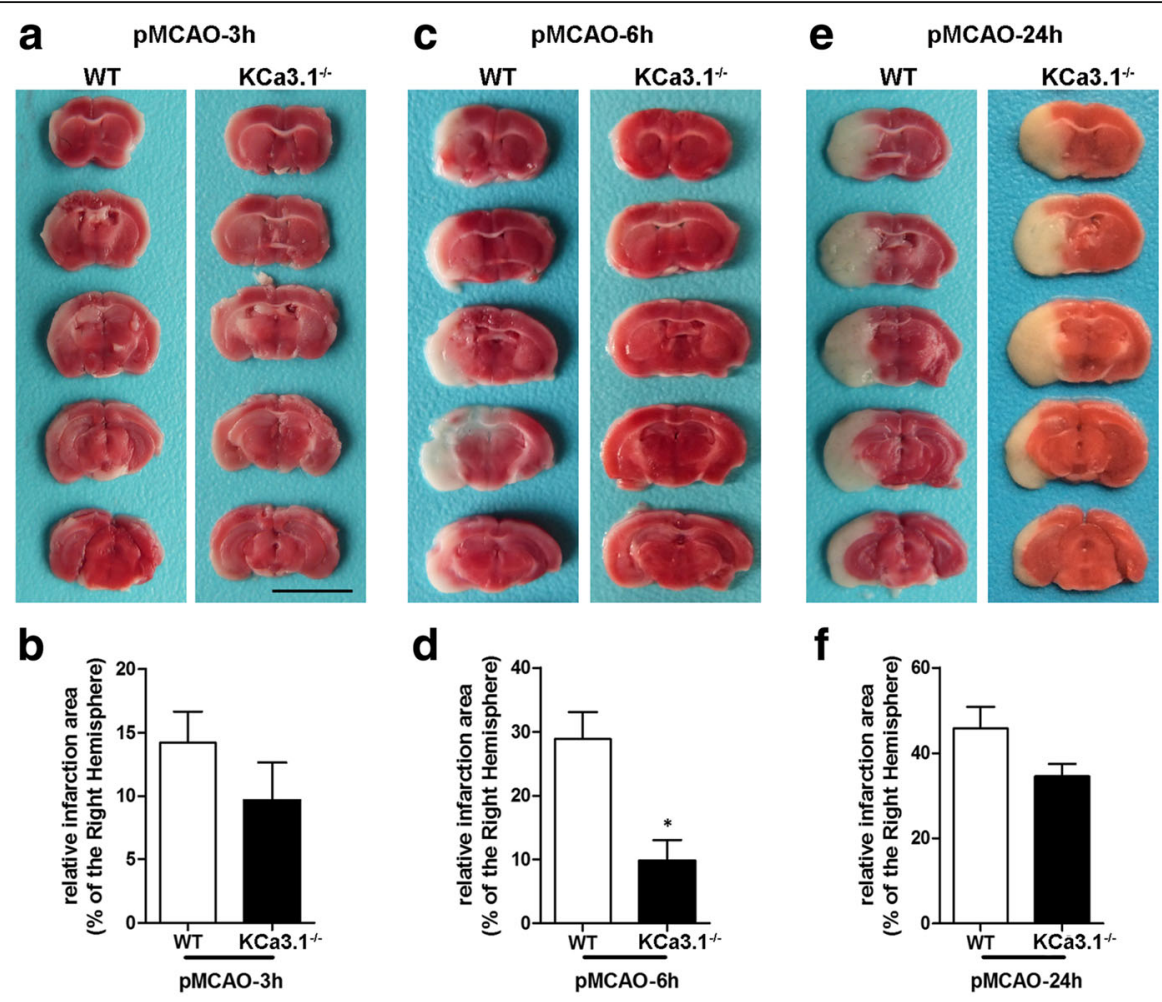

\section{f}

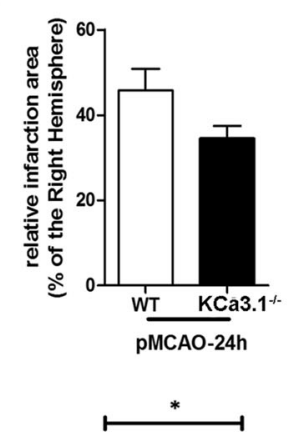

g

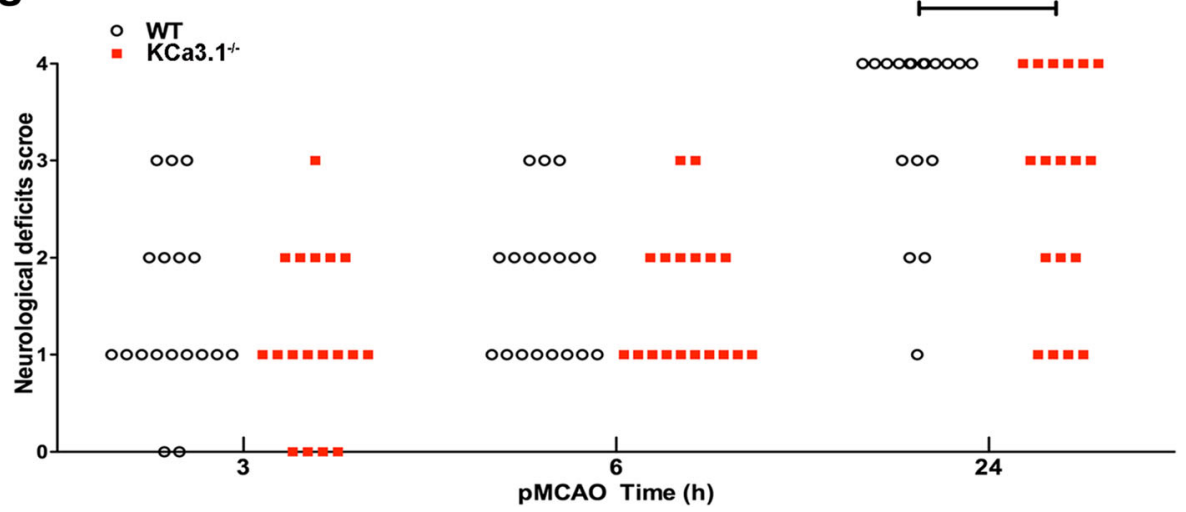

Fig. 2 KCa3.1 deficiency reduces infarction volume and improves of neurological conditions. Focal cerebral ischemia was induced by pMCAO. a, c, and $\mathbf{e}$ Representative TTC staining of five corresponding coronal brain sections of a 10-week-old male WT mouse and a 10 week-old male KCa3.1 $1^{-1-}$ mouse after $3 \mathrm{~h}(\mathbf{a}), 6 \mathrm{~h}(\mathbf{c})$, and $24 \mathrm{~h}(\mathbf{e})$ of pMCAO. b, d, and $\mathbf{f}$. Quantitative analysis of infarction volume in a, c, and e, respectively. Data are presented as means \pm SEM. $n=6 .{ }^{*} p<0.05$, unpaired, two-tailed Student's $t$ test compared with ischemic WT group. $\mathbf{g}$ Neurological deficits were assessed at 3, 6, and $24 \mathrm{~h}$ after PMCAO. Significance: ${ }^{*} p<0.05$ vs WT group $(n=18)$. Mann-Whitney test compared with WT mice. The survival rate of $24 \mathrm{~h}$ after PMCAO was obviously higher in the KCa3.1 $1^{-/-}$group than that in the WT group (66.7 vs $37.5 \%$, respectively), and significant differences was observed $(p=0.0486$, chi-square test $)$

reported before, activation of KCa3.1 hyperpolarizes nonexcitable cells such as airway smooth muscle cells [25] and pancreatic cancer cells [30]; this hyperpolarization enhances the driving force for $\mathrm{Ca}^{2+}$ influx. To evaluate the role of KCa3.1 in OGD activation of astrocytes, the KCa3.1 pharmacological activator 1-ethylbenzimidazolinone (EBIO) was used to activate KCa3.1 [31] with and without OGD. As shown in Fig. 5a, $200 \mu \mathrm{M}$ 1-EBIO induced a larger hyperpolarization (as measured by DiBAC4(3) fluorescence intensity) in the $1 \mathrm{~h}$ OGD-treated astrocytes as compared to control cells, likely due to enhanced $\mathrm{K}^{+}$efflux upon increased KCa3.1 activation. We then used the TRPV4 channel antagonist HC 067047 to test the role of TRPV4 channels in regulating membrane potential during 1-EBIOinduced KCa3.1 activation. Blockade of TRPV4 attenuated the level of 1-EBIO-mediated membrane hyperpolarization in OGD-induced astrocytes $(p<0.001$, Fig. 5a, b). In addition, $10 \mu \mathrm{M}$, but not $1 \mu \mathrm{M}, \mathrm{KCa} 3.1$ selective blocker 


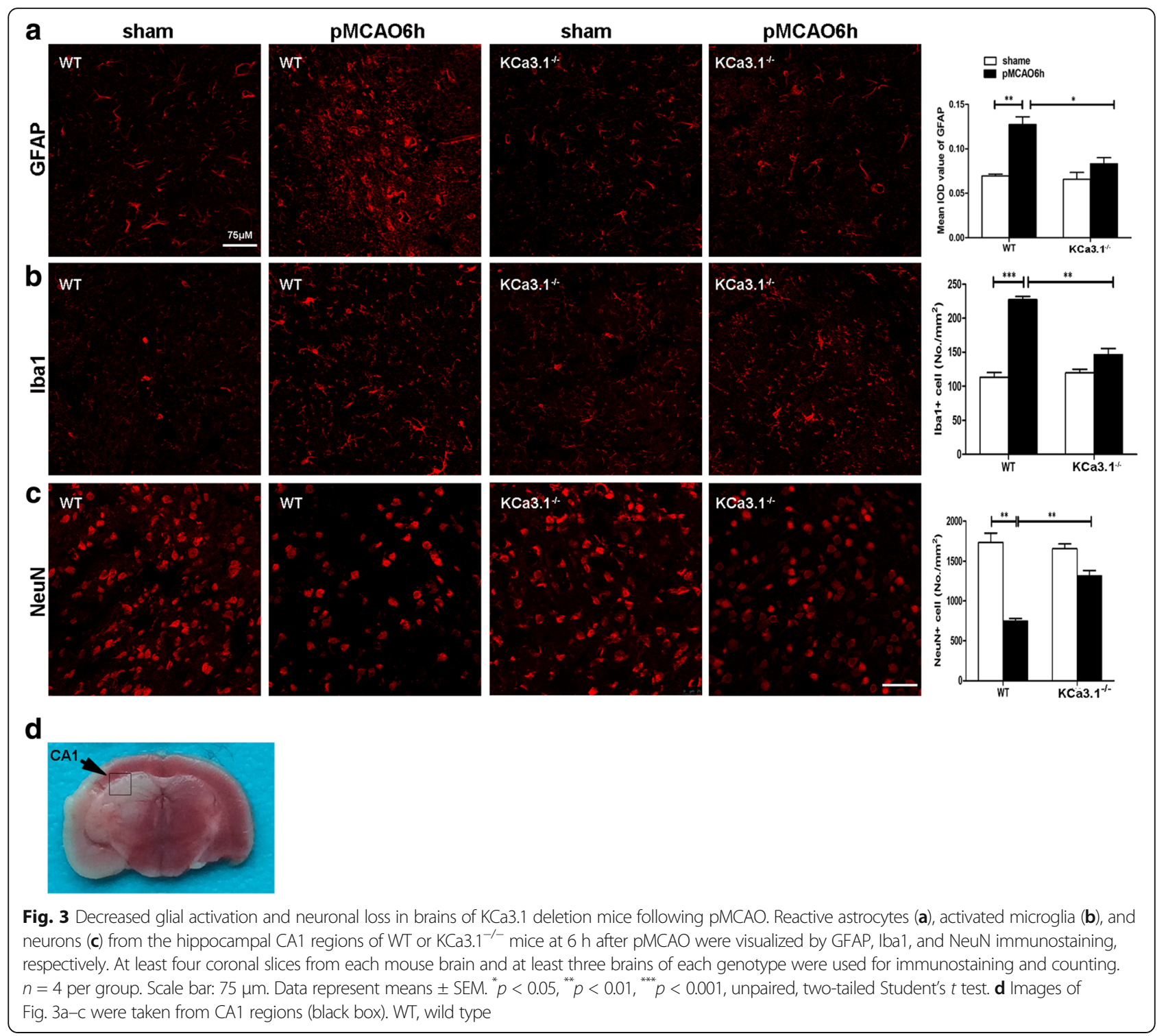

TRAM-34 attenuated $200 \mu \mathrm{M}$ 1-EBIO-induced membrane hyperpolarization in $1 \mathrm{~h}$ OGD-treated astrocytes $(p<0.001$, Fig. 5 c, d).

It was reported that as the downstream component of the TRPV4 transduction pathway, a genetic deficit of $\mathrm{KCa} 3.1$ reduced lung damage and pulmonary circulatory collapse induced by TRPV4 channel activation [32]. We therefore measured the change in membrane potential in both WT and $\mathrm{KCa} 3.1 \mathrm{KCa} 3.1^{-/-}$astrocytes following the addition of the TRPV4 channel agonist $10 \mu \mathrm{M}$ RN1747 along with OGD. We found that hyperpolarization in response to RN1747 was reduced in the $\mathrm{KCa} 3.1^{-/-}$astrocytes, compared with the WT cells $(p<0.001$, Fig. $5 \mathrm{e}, \mathrm{f})$, both in normoxia and in response to OGD.

\section{KCa3.1 activation induces calcium entry in astrocytes} through TRPV4 calcium channel during oxygen-glucose deprivation

It has been suggested that the $\mathrm{Ca}^{2+}$ influx resulting from activation of TRPV4 channels is leveraged by the high $\mathrm{Ca}^{2+}$ sensitivity of $\mathrm{KCa} 3.1$ and $\mathrm{KCa} 2$ to cause vascular endothelium vasodilation [33]. To evaluate the potential activation of $\mathrm{KCa} 3.1$ channels by OGD, we measured $\left[\mathrm{Ca}^{2}\right.$ $\left.{ }^{+}\right]_{\mathrm{i}}$ in response to activation of $\mathrm{KCa} 3.1$ channels by 1 -EBIO in control astrocytes and in astrocytes subjected to $1 \mathrm{~h}$ of OGD. We found that $200 \mu \mathrm{M} 1-\mathrm{EBIO}$ induced a larger increase in $\left[\mathrm{Ca}^{2+}\right]_{\mathrm{i}}$ in the $1 \mathrm{~h}$ OGD-treated astrocytes as compared to the control cells $(p<0.001$, Fig. $5 \mathrm{~g}, \mathrm{~h}$ ). We then used $\mathrm{HC} 067047$ to test the role of TRPV4 channels in the $\mathrm{Ca}^{2+}$ influx during OGD and 1-EBIO-induced KCa3.1 

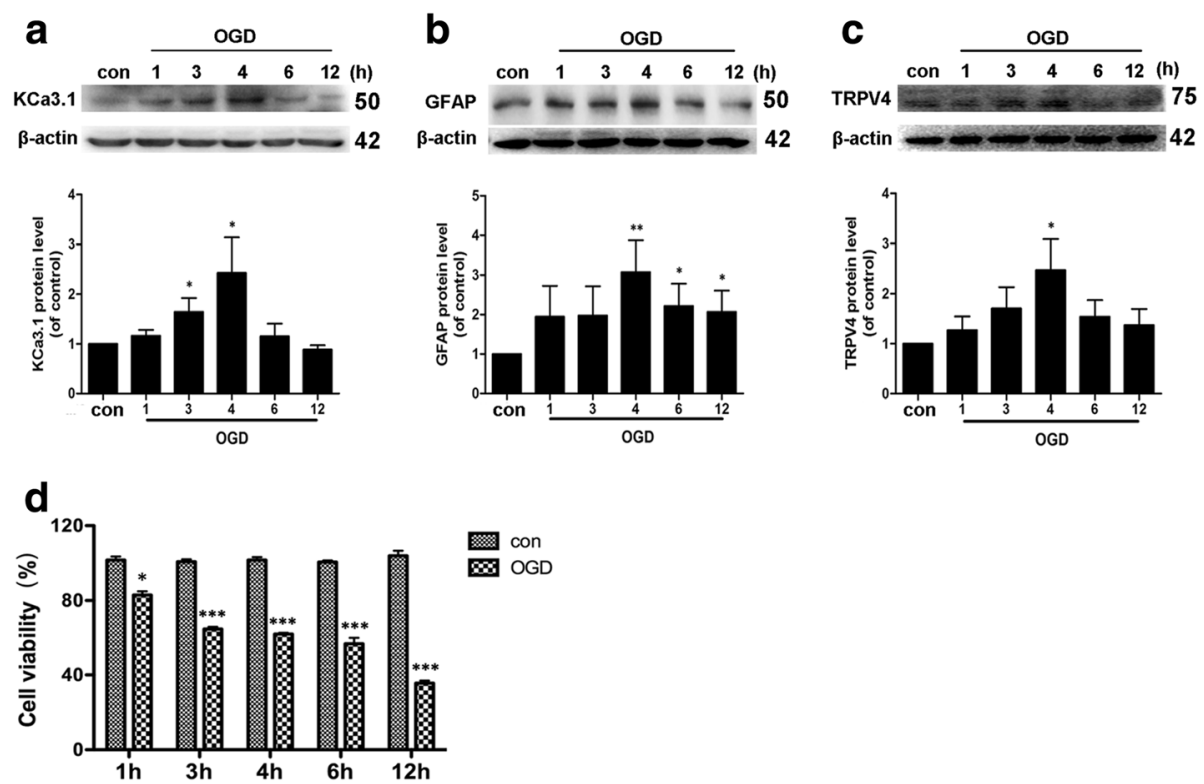

Fig. 4 Upregulation of KCa3.1, GFAP, and TRPV4 channels following OGD in cultured astrocytes. Western blot analysis of (a) KCa3.1, (b) GFAP, and (c) TRPV4 expression after OGD-treatment for 0, 1, 3, 4, 6, 12 h. Data represent the means \pm SEM of KCa3.1, GFAP, and TRPV4 density normalized to $\beta$-actin values for $n=3$ cultures. ${ }^{*} p<0.05,{ }^{* *} p<0.01$, one-way ANOVA followed by the Dunnett's multiple comparison test compared with control. (d) Cell viability was determined by the CCK-8 assay. The values represent the percentage of cells viability induced by $1,3,4,6$, or 12 h of OGD $(n=4)$. Data represent means \pm SEM. ${ }^{*} p<0.05,{ }^{* * *} p<0.001$, unpaired, two-tailed Student's $t$ test compared with control. Con control, OGD oxygen-glucose deprivation

activation; we found that blockade of TRPV4 channels attenuated the level of 1 -EBIO-mediated $\mathrm{Ca}^{2+}$ increase in OGD-induced astrocytes ( $p<0.001$, Fig. $5 \mathrm{~g}, \mathrm{~h}$ ). To further confirm that $\mathrm{KCa} 3.1$ activation induced the $\left[\mathrm{Ca}^{2+}\right]_{\mathrm{i}}$ increase, TRAM-34 (1 and $10 \mu \mathrm{M})$ was used in the same experiments. In the presence of 1 and $10 \mu \mathrm{M}$ TRAM-34, the [ $\mathrm{Ca}^{2}$ $\left.{ }^{+}\right]_{\mathrm{i}}$ increase induced by $200 \mu \mathrm{M} 1$-EBIO was attenuated in both the $1 \mu \mathrm{M}(p<0.01$, Fig. $5 \mathrm{i}, \mathrm{j})$ and $10 \mu \mathrm{M}(p<0.001$, Fig. 5i, j) TRAM-34 treatment of 1 h OGD-astrocytes.

To evaluate the effect of OGD on TRPV4 channels, we used $10 \mu \mathrm{M}$ RN1747 in WT and $\mathrm{KCa}^{-1} 1^{-/}$astrocytes with and without OGD. $\left[\mathrm{Ca}^{2+}\right]_{i}$ was measured before and after the application of OGD $1 \mathrm{~h}$. In the $\mathrm{KCa} 3.1^{-/-}$ astrocytes, the $\mathrm{Ca}^{2+}$ influx induced by RN1747 was drastically reduced as compared with the WT cells $(p<0.001$, Fig. $5 \mathrm{k}, \mathrm{l})$. Taken together, our data showed that TRPV4 channels mediated the plasma membrane hyperpolarization-evoked $\left[\mathrm{Ca}^{2+}\right]_{\mathrm{i}}$ increase due to activation of $\mathrm{KCa} 3.1$.

\section{KCa3.1 and TRPV4 channels regulated astrogliosis}

The above results indicate that $\mathrm{KCa} 3.1$ and TRPV4 are functionally linked. The question then arises as to whether they are physically associated with each other. The physical interaction between KCa3.1 and TRPV4 channels was further tested. Confocal analysis of double-labeled staining showed that KCa3.1 and TRPV4 channels co-localized in normal mouse brain (Fig. 6a, b) and primary cultured astrocytes (Fig. 6c, d). Histograms represent the ratio of the mean Pearson correlation coefficient using Leica LAS AF Lite software. The Pearson correlation values range from -1 to +1 . A correlation of 1 indicates complete colocalization between the two proteins. A correlation of - 1 indicates a negative interaction, and a correlation of 0 indicates no co-localization between the two proteins. When double-labeled staining of $\mathrm{KCa} 3.1$ and TRPV4 channels, co-localization was observed in normal mouse brain (Fig. 6a, b) and primary cultured astrocytes (Fig. 6c, d). As shown in Fig. 6e, Pearson correlation coefficients are 0.57 (mouse brain) and 0.49 (astrocytes), confirming colocalization between $\mathrm{KCa} 3.1$ and TRPV4.

The involvement of the KCa3.1 and TRPV4 in regulating the emergence of astrogliosis induced by $4 \mathrm{~h}$ OGD was studied by using antagonists of these two channels. In the presence of either TRAM-34 $(1 \mu \mathrm{M})$ or $\mathrm{HC}$ $067047(10 \mu \mathrm{M})$, upregulation of GFAP was attenuated $(p<0.05$, Fig. 7a, b). Moreover, astrocytes from KCa3.1 $\mathrm{KCa} 3.1^{-1-}$ mice exhibited a decrease in GFAP expression induced by 4 h OGD treatment $(p<0.001$, Fig. $7 \mathrm{c}, \mathrm{d})$ as compared to WT astrocytes. These results suggested that KCa3.1 and TRPV4 are both involved in the process of astrogliosis induced by OGD.

\section{Discussion}

The major findings of this study are that the $\mathrm{KCa} 3.1$ channel contributes to reactive astrogliosis following 

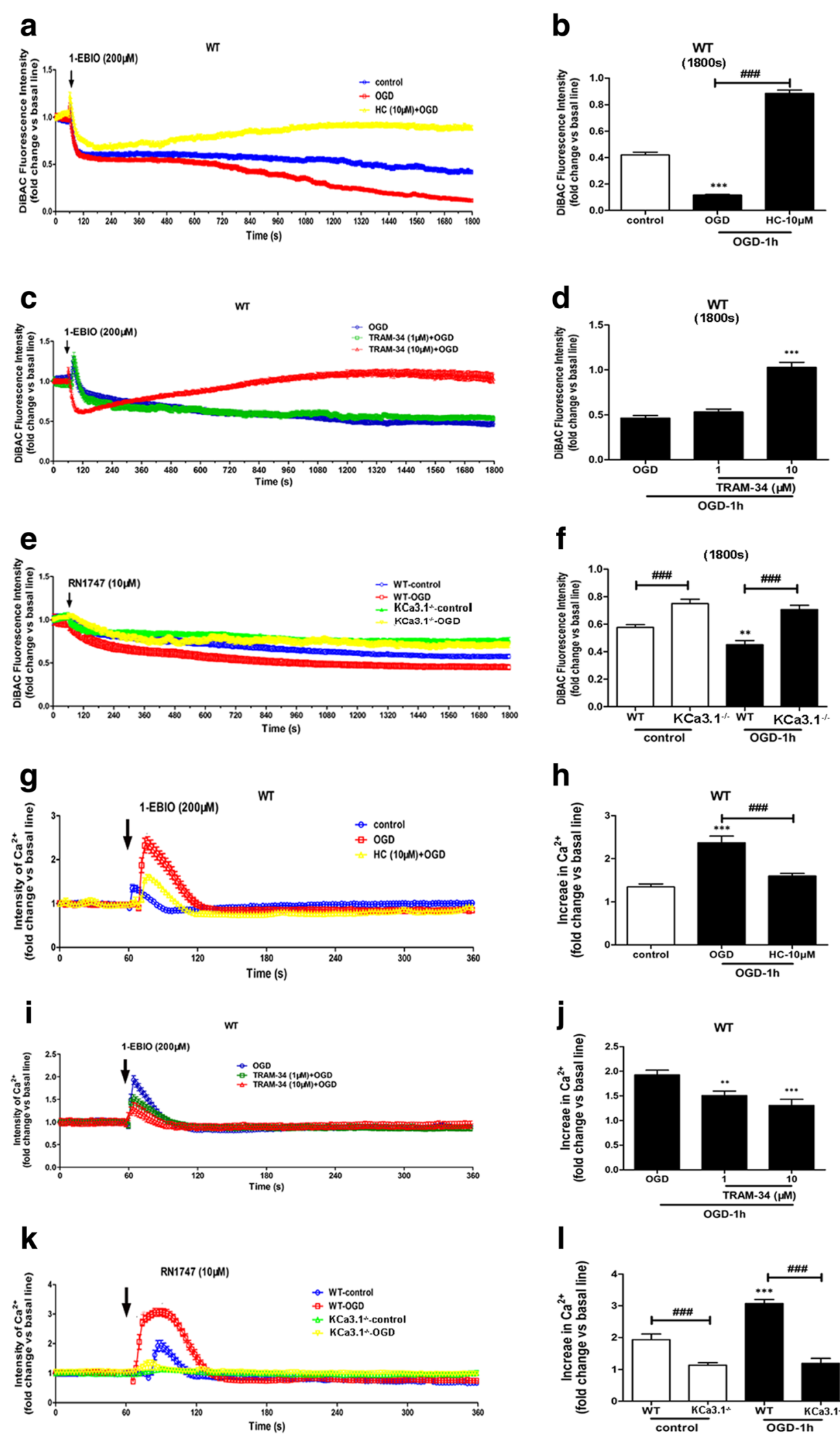

I

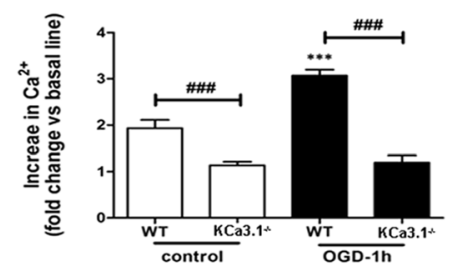

Fig. 5 (See legend on next page.) 
(See figure on previous page.)

Fig. 5 Role of TRPV4 and KCa3.1 in alteration of membrane potential and $\mathrm{Ca}^{2+}$ entry in astrocytes following OGD. a-f Changes in membrane potential in response to activation of KCa3.1 channels and TRPV4 channels in astrocytes exposed to OGD 1 h. a, b 1-EBIO was added to WT astrocytes and membrane potential measured with or without OGD or HC 067047. Data are presented as means \pm SEM. $n=10-20 .{ }^{* * *} p<0.001$ vs control. ${ }^{\# \# \#} p<0.001$ vs OGD. c, d 1-EBIO was added to WT astrocytes and membrane potential measured with or without OGD or TRAM-34 (1 and $10 \mu M)$. Data are presented as

means \pm SEM. $n=10-20 .{ }^{* * *} p<0.001$ vs OGD. e, f RN1747 was added to WT or KCa3.1 KCa3.1 $1^{-1-}$ astrocytes and membrane potential measured with or without OGD. b, d, f Summary of data showing the membrane potential in $\mathbf{a}$, c, and e at 1800s. Data are presented as means \pm SEM. $n=10-20 .{ }^{* *} p<0.01$ vs WT control, ${ }^{\# \# \#} p<0.001$ vs WT control or WT OGD. $\mathbf{g}-\mathbf{I}$ Changes in $\left[\mathrm{Ca}^{2+}\right]_{\mathrm{i}}$ in response to activation of KCa3.1 channels and TRPV4 channels in astrocytes exposed to OGD 1 h. $\mathbf{g}, \mathbf{h}$ 1-EBIO was added to WT astrocytes and $\left[\mathrm{Ca}^{2+}\right]_{\mathrm{i}}$ measured with or without OGD or HC 067047. Data are presented as means \pm SEM. $n=10-20 .{ }^{* * *} p<0.001$ vs control. ${ }^{\# \#} p<0.001$ vs OGD. $\mathbf{i}, \mathbf{j}$ 1-EBIO was added to WT astrocytes and $\left[\mathrm{Ca}^{2+}\right]_{\mathrm{i}}$ measured with or without OGD or TRAM-34 (1 and $10 \mu \mathrm{M}$ ). Data are presented as means \pm SEM. $n=10-20 .{ }^{* *} p<0.01,{ }^{* * *} p<0.001$ vs OGD. k, I RN1747 was added to WT or KCa3.1 KCa3.1 ${ }^{-/-}$astrocytes and $\left[\mathrm{Ca}^{2+}\right]_{\mathrm{i}}$ measured with or without OGD. $\mathbf{h}, \mathbf{j}$, I Summary of data showing the $\left[\mathrm{Ca}^{2+}\right]_{\mathrm{i}}$ in $\mathbf{h}, \mathbf{j}$, and $\mathbf{I}$ at $70-80$ s. Data are presented as means \pm SEM. $n=10-20 .{ }^{* * *} p<0.001$ vs WT control, ${ }^{\# \# \#} p<0.001$ vs WT control or WT OGD. Statistical analysis was performed using unpaired, two-tailed Student's $t$ test. 1-EBIO, 1-ethyl-2-benzimidazolinone, OGD oxygen-glucose deprivation, WT wild type, HC HC 067047

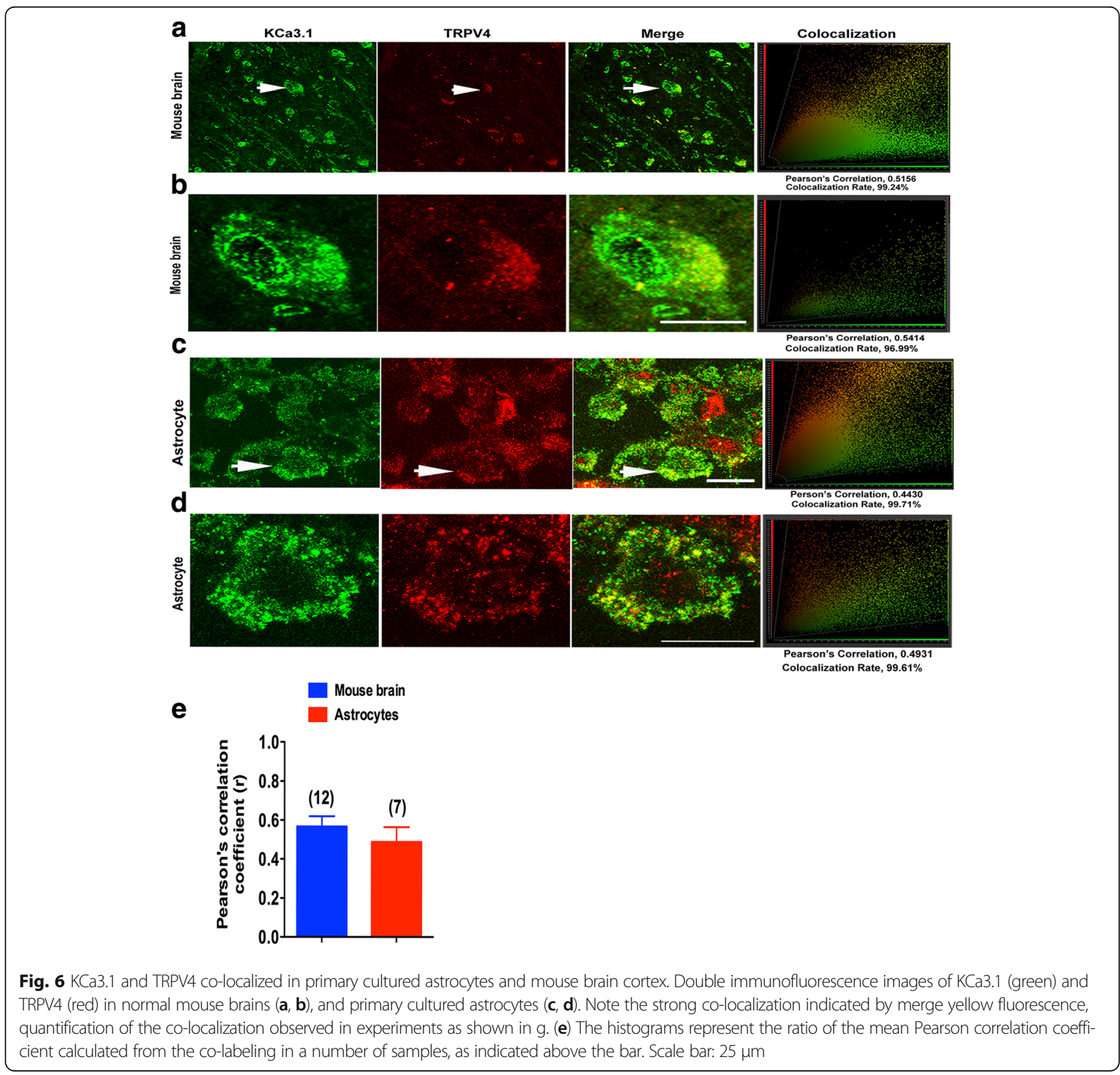



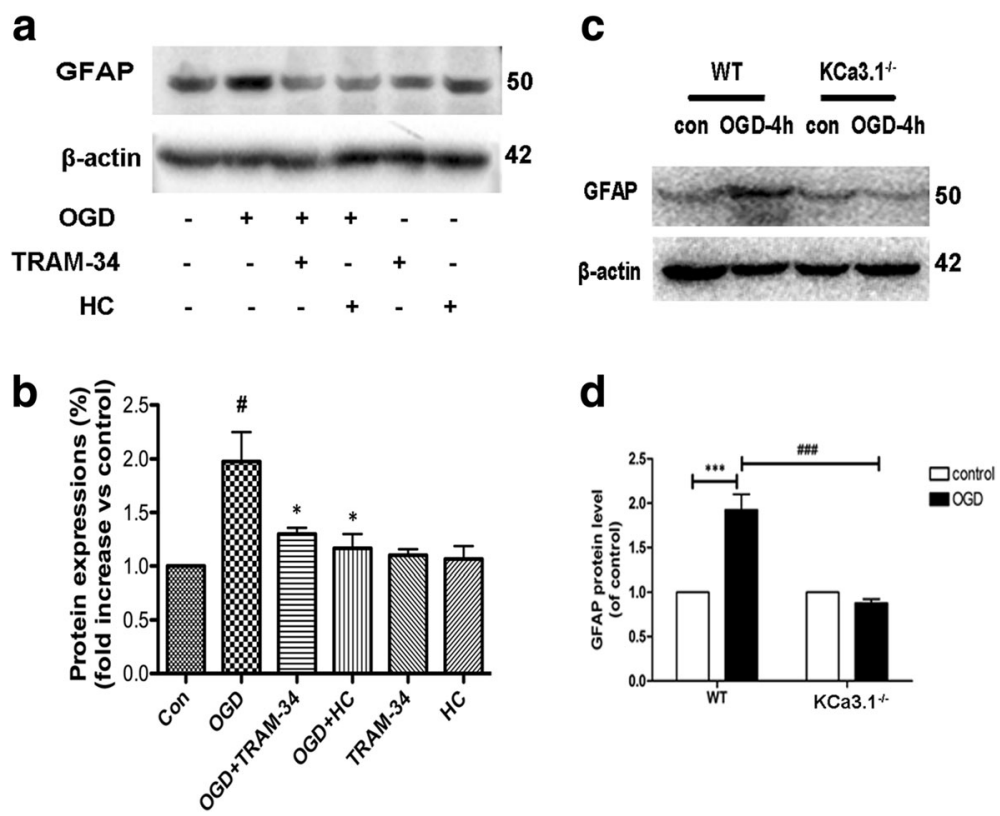

Fig. 7 Involvement of KCa3.1 in OGD-induced reactive astrogliosis. a, b Representative western blot showing GFAP expression in cultured astrocytes treated with OGD for $4 \mathrm{~h}$ in the presence of $1 \mu \mathrm{M}$ TRAM-34 and $10 \mu \mathrm{M} \mathrm{HC}$ 067047. Quantification of western blot for GFAP expression $(n=3)$. Data are presented as means \pm SEM. ${ }^{\#} p<0.05$ vs control, ${ }^{*} p<0.05$ vs OGD alone. $\mathbf{c}, \mathbf{d}$ Representative western blot and quantification of GFAP expression after $4 \mathrm{~h}$ OGD treatment in WT and KCa3.1 KCa3.1 ${ }^{-/-}$astrocytes $(n=3-4) .{ }^{* * *} p<0.001,{ }^{\# \# \#} p<0.001$. One-way ANOVA followed by the Dunnett's multiple comparison test. Con control, WT wild type

ischemia, as shown in both OGD-treated astrocytes in vitro and the brains of mice subject to pMCAO in vivo, that $\mathrm{KCa} 3.1$ regulated $\mathrm{Ca}^{2+}$ influx and membrane potential by functional cooperation with the TRPV4 channel in OGD-treated astrocytes. The expression of both channels was increased during astrogliosis and blockade either KCa3.1 or TRPV4 attenuated the astrogliosis process. Additionally, double-labeled staining experiments showed the co-localization between TRPV4 and KCa3.1 in mouse brain and primary astrocytes, where they might cooperate to regulate the reactive astrogliosis.

We provided genetic target validation of the role of KCa3.1 by demonstrating that mice with a gene deletion of KCa3.1 exhibited significantly reduced pathology after pMCAO. This was manifested as both reduced infarct area after the insult as well as reduced astrogliosis, microglial activation and neuron loss. This is consistent with recent studies that demonstrated that pharmacological blockade of $\mathrm{KCa} 3.1$ or gene silence reduces infarct size and other neurological deficits in rats or mice [34]. Moreover, in the present study, we extended this hypothesis to show that KCa3.1 acted as an endogenous sensor of $\mathrm{Ca}^{2+}$ influx caused by activation of TRPV4. We found that blockade of either channel could reduce astrogliosis. In addition, we found that these channels could be co-localization.

The lack of voltage-gated $\mathrm{Ca}^{2+}$ channels in nonexcitable cells allows $\mathrm{KCa} 3.1$ to act as $\mathrm{Ca}^{2+}$ detectors and $\mathrm{Ca}^{2+}$ amplifiers. Activation of $\mathrm{KCa} 3.1$ induced $\mathrm{K}^{+}$efflux and membrane hyperpolarization, which ultimately upregulated the driving force for $\mathrm{Ca}^{2+}$ influx $[35,36]$, and further $\mathrm{KCa} 3.1$ channels will be activated in a positive feedback loop. $\mathrm{KCa} 3.1-\mathrm{Ca}^{2+}$ channels were involved in non-excitable cells activation process [35]. An interaction between KCa3.1 and TRPV4 channels has been found in several diseases, during which $\mathrm{Ca}^{2+}$ dynamics induced by $\mathrm{KCa} 3.1$ were dependent on $\mathrm{Ca}^{2+}$ influx via TRPV4 channels [37, 38]. There was a functional co7upling between KCa3.1 and TRPV4 to regulate $\mathrm{Ca}^{2+}$ levels leading to pulmonary circulatory collapse and hemorrhage [39].

An interaction of TRPV4 and KCa channels has been found in several other brain functions. In retinal ganglion cells, activation of TRPV4 induced apoptosis due to $\mathrm{Ca}^{2+}$ overload [40]. Shi et al. [41] reported that $\mathrm{Ca}^{2+}$ influx via TRPV4 channels involved in infrasoundinduced activation of astrocytes and microglia, and then neuronal death. Astrocytes volume was regulated by TRPV4/AQP4 complex through water transport and calcium homeostasis. Over activation of the interaction of TRPV4/AQP4 complex would trigger the pathological swelling and reactive gliosis [42]. $\mathrm{Ca}^{2+}$ influx through TRPV4 channels activated the large $\mathrm{Ca}^{2+}$-activated $\mathrm{K}^{+}$ channel (BK), and TRPV4/BK functional coupling regulated bladder contractility in the storage phase [43]. Gene deletion of KCa3.1 channels attenuated lung 
damage and pulmonary circulatory collapse caused by TRPV4 activation. In addition, these data are consistent with recent studies that suggested that the $\mathrm{KCa}$ channels might serve as amplifiers of the $\mathrm{Ca}^{2+}$ signaling through TRP channels [44] and data demonstrating a coupling of the two types of channels in osmosensors in the paraventricular nucleus [45]. Recently, it was reported that calcium-gated $\mathrm{K}^{+}$channels of the KCa1.1- and KCa3.1type couple intracellular $\mathrm{Ca}^{2+}$ signals to membrane hyperpolarization in mesenchymal stromal cells from the human adipose tissue (Tarasov et al. 2017). It might explain the reason that stimulation of TRPV4 agonist RN1747 still caused membrane hyperpolarization in the $\mathrm{KCa} 3.1^{-1-}$ astrocytes as shown in Fig. 6e.

Reactive astrocytes are involved in many pathological processes of CNS diseases, such as stroke, traumatic brain injury, and AD [46]. During the process of neuroinflammation, activated microglia induce the phenotypic switch of astrocytes from a quiescent to a reactive phenotype. Neurotoxic reactive astrocytes, termed A1 astrocytes, are induced by activated microglia, which lose the ability to support neurons and oligodendrocyte survival and synaptogenesis [47]. In our previous studies, we showed that a similar phenotype can be induced in culture using TGF- $\beta$ [17], and that blockade or deletion of the $\mathrm{KCa} 3.1$ channel prevented the emergence of the reactive phenotype. Whether this mechanism of astrocyte activation depends upon the astrocytic TRPV4 channels is a subject for future investigation.

KCa3.1 is thought to regulate microglial activation such as migration and neurotoxicity induced by activated microglia in vitro $[48,49]$. Higher densities of Kv1.3, KCa3.1, and Kir2.1 currents were detected in microglia from the infarcted area of reversible MCAO than that from non-infarcted control brains. Similarly, strong KCa3.1 immunoreactivity was also found on activated microglia/macrophages of human infarcts [34]. However, we did not find any obvious co-localization between $\mathrm{KCa} 3.1$ and microglia in the brains of pMCAO mice by immunofluorescence staining. It may be that the different model of ischemic stroke (reversible MCAO vs pMCAO) as well as the different detection method (patch clamp vs immunofluorescence staining) might be the reason.

\section{Conclusions}

In conclusion, these data suggested that KCa3.1 and TRPV4 channels forms a signaling complex involved in maintaining abnormally high $\left[\mathrm{Ca}^{2+}\right]_{i}$ levels to drive phenotype switch of astrogliosis during ischemia stroke. Gene deletion of KCa3.1 attenuated infarct area and reduced neuron loss and gliosis in pMCAO, which may have therapeutic utility in ischemia stroke associated with abnormally high $\left[\mathrm{Ca}^{2+}\right]_{\mathrm{i}}$ in astrogliosis.

\section{Additional files}

Additional file 1: Figure S1. Cerebral blood flow (CBF) of ischemic brain hemisphere before and during permanent middle cerebral artery occlusion (pMCAO) was monitored by transcranial laser Doppler. The arrow depicted the start of pMCAO. (TIFF $58 \mathrm{~kb}$ )

Additional file 2: Figure S2. Western blot analysis of lysates from 10week-old male WT mice following 1, 3, 6, or $12 \mathrm{~h}$ of pMCAO analyzed by antibodies to KCa3.1 (A) and GFAP (B). (TIFF 223 kb)

Additional file 3: Figure S3. GFAP ${ }^{+}$reactive astrocytes and $\mathrm{Iba}^{+}$ activated microglia from the cortex and hippocampal regions of WT or $\mathrm{KCa} 3.1^{-1-}$ mice brain at $6 \mathrm{~h}$ after pMCAO were visualized by immunostaining. Scale bar: $200 \mu \mathrm{m}$. WT, wild type. (TIFF $7211 \mathrm{~kb}$ )

\section{Abbreviations}

1-EBIO: 1-Ethylbenzimidazolinone; GFAP: Glial fibrillary acidic protein; KCa3.1: Intermediate-conductance calcium-activated potassium channel; pMCAO: Permanent middle cerebral artery occlusion; TRAM-34: 1-((2chlorophenyl) (diphenyl) methyl)-1H-pyrazole; TRPV4: Transient receptor potential vanilloid 4

\section{Acknowledgements}

We thank Dr. Tianle Xu and Dr. Jingjing Wang (Department of Anatomy, Histology and Embryology, Collaborative Innovation Center for Brain Science, Shanghai Key Laboratory for Tumor Microenvironment and Inflammation, Shanghai Jiao Tong University School of Medicine, Shanghai, China.) for kindly providing the Transcranial laser Doppler.

\section{Funding}

This work was supported by Science and Technology Commission of Shanghai Municipality grant 16ZR1418700, National Natural Science Foundation of China grant 81773699 . The authors declare that the research was conducted in the absence of any commercial or financial relationships that could be construed as a potential conflict of interest.

\section{Availability of data and materials}

Data sharing is not applicable to this article as no datasets were generated or analyzed during the current study.

\section{Authors' contributions}

ZY supervised the entire project, designed the research, and wrote the paper. $\mathrm{HC}$ and $\mathrm{HG}$ conceived and designed the experiments, interpreted and analyzed the data, and supervised all the experimental procedure. MY and TW conceived and designed the experiments, performed the research interpreted, and analyzed the data. QL and XG performed the research and analyzed the data. GC and YW analyzed the data and critically revised the manuscript. All authors read and approved the final manuscript.

\section{Ethics approval and consent to participate}

The study (ethics protocol number: A-2015-010) was approved by the Animal Care and Use Committee of the Shanghai Jiao Tong University School of Medicine, Shanghai, China.

\section{Consent for publication}

Not applicable.

\section{Competing interests}

The authors declare that they have no competing interests.

\section{Publisher's Note}

Springer Nature remains neutral with regard to jurisdictional claims in published maps and institutional affiliations.

\section{Author details}

'Department of Pharmacology, Institute of Medical Sciences, Shanghai Jiao Tong University School of Medicine, Shanghai 200025, China. ${ }^{2}$ Experimental Teaching Center of Basic Medicine, School of Medicine, Shanghai Jiao Tong University, Shanghai 200025, China. ${ }^{3}$ Developmental Neurobiology Section, 
Division of Intramural Research, National Heart, Lung, and Blood Institute, National Institutes of Health, Bethesda, MD 20892, USA

\section{Received: 19 July 2017 Accepted: 27 September 2017} Published online: 16 October 2017

\section{References}

1. Nedergaard M, Rodriguez JJ, Verkhratsky A. Glial calcium and diseases of the nervous system. Cell Calcium. 2010;47:140-9.

2. Di L, Srivastava S, Zhdanova O, Ding Y, Li Z, Wulff H, Lafaille M, Skolnik EY, Inhibition of the k+ channel kca3.1 ameliorates t cell-mediated colitis. Proc Natl Acad Sci U S A. 2010;107:1541-6.

3. Toyama K, Wulff H, Chandy KG, Azam P, Raman G, Saito T, Fujiwara Y, Mattson DL, Das S, Melvin JE, Pratt PF, Hatoum OA, Gutterman DD, Harder $\mathrm{DR}$, Miura $\mathrm{H}$. The intermediate-conductance calcium-activated potassium channel kca3.1 contributes to atherogenesis in mice and humans. J Clin Invest. 2008;118:3025-37.

4. ZH Y, Wang YX, Song Y, HZ L, Hou LN, Cui YY, Chen HZ. Up-regulation of kca3.1 promotes human airway smooth muscle cell phenotypic modulation. Pharmacol Res. 2013:77:30-8.

5. Bouhy D, Ghasemlou N, Lively S, Redensek A, Rathore Kl, Schlichter LC, David S. Inhibition of the ca(2)(+)-dependent k(+) channel, kcnn4/kca3.1, improves tissue protection and locomotor recovery after spinal cord injury. J Neurosci. 2011:31:16298-308.

6. Mauler F, Hinz V, Horvath E, Schuhmacher J, Hofmann HA, Wirtz S, Hahn MG, Urbahns K. Selective intermediate-/small-conductance calciumactivated potassium channel (kcnn4) blockers are potent and effective therapeutics in experimental brain oedema and traumatic brain injury caused by acute subdural haematoma. Eur J Neurosci. 2004;20:1761-8.

7. Wei T, Yi M, Gu W, Hou L, Lu Q, Yu Z, Chen H. The potassium channel kca3. 1 represents a valid pharmacological target for astrogliosis-induced neuronal impairment in a mouse model of alzheimer's disease. Front Pharmacol. 2016;7:528.

8. Chen YJ, Wallace BK, Yuen N, Jenkins DP, Wulff H, O'Donnell ME. Bloodbrain barrier kca3.1 channels: Evidence for a role in brain na uptake and edema in ischemic stroke. Stroke. 2015;46:237-44.

9. Chen YJ, Nguyen HM, Maezawa I, Grossinger EM, Garing AL, Kohler R, Jin LW, Wulff H. The potassium channel kca3.1 constitutes a pharmacological target for neuroinflammation associated with ischemia/reperfusion stroke. J Cerebral Blood Flow Metab. 2016;36:2146-61.

10. Shibasaki K, Hosoi N, Kaneko R, Tominaga M, Yamada K. Glycine release from astrocytes via functional reversal of glyt1. J Neurochem. 2017;140:395-403.

11. Jie P, Lu Z, Hong Z, Li L, Zhou L, Li Y, Zhou R, Zhou Y, Du Y, Chen L, Chen L. Activation of transient receptor potential vanilloid 4 is involved in neuronal injury in middle cerebral artery occlusion in mice. Mol Neurobiol. 2016:53:8-17.

12. Bai JZ, Lipski J. Differential expression of trpm2 and trpv4 channels and their potential role in oxidative stress-induced cell death in organotypic hippocampal culture. Neurotoxicology. 2010;31:204-14.

13. Lipski J, Park TI, Li D, Lee SC, Trevarton AJ, Chung KK, Freestone PS, Bai JZ. Involvement of trp-like channels in the acute ischemic response of hippocampal ca1 neurons in brain slices. Brain Res. 2006;1077:187-99.

14. Li L, Qu W, Zhou L, Lu Z, Jie P, Chen L, Chen L. Activation of transient receptor potential vanilloid 4 increases nmda-activated current in hippocampal pyramidal neurons. Front Cell Neurosci. 2013;7:17.

15. Butenko O, Dzamba D, Benesova J, Honsa P, Benfenati V, Rusnakova V, Ferroni S, Anderova M. The increased activity of trpv4 channel in the astrocytes of the adult rat hippocampus after cerebral hypoxia/ischemia. PLoS One. 2012;7:e39959.

16. Yi M, Dou F, Lu Q, Yu Z, Chen H. Activation of the kca3.1 channel contributes to traumatic scratch injury-induced reactive astrogliosis through the jnk/c-jun signaling pathway. Neurosci Lett. 2016;624:62-71.

17. Yu Z, Yu P, Chen H, Geller HM. Targeted inhibition of kca3.1 attenuates tgfbeta-induced reactive astrogliosis through the smad2/3 signaling pathway. J Neurochem. 2014;130:41-9

18. Begenisich T, Nakamoto T, Ovitt CE, Nehrke K, Brugnara C, Alper SL, Melvin JE. Physiological roles of the intermediate conductance, ca2+-activated potassium channel kcnn4. J Biol Chem. 2004;279:47681-7.

19. Chu HX, Kim HA, Lee S, Broughton BR, Drummond GR, Sobey CG. Evidence of ccr2-independent transmigration of ly $6 \mathrm{c}(\mathrm{hi})$ monocytes into the brain after permanent cerebral ischemia in mice. Brain Res. 2016;1637:118-27.
20. Tanaka Y, Fukumitsu H, Soumiya H, Yoshimura S, Iwama T, Furukawa S. 2decenoic acid ethyl ester, a compound that elicits neurotrophin-like intracellular signals, facilitating functional recovery from cerebral infarction in mice. Int J Mol Sci. 2012;13:4968-81.

21. Konig S, Browne S, Doleschal B, Schernthaner M, Poteser M, Machler $H$, Wittchow E, Braune M, Muik M, Romanin C, Groschner K. Inhibition of orai1mediated $\mathrm{ca}(2+)$ entry is a key mechanism of the antiproliferative action of sirolimus in human arterial smooth muscle. Am J Phys Heart Circ Phys. 2013;305:H1646-57.

22. Sun $\mathrm{S}$, Chen $\mathrm{G}, \mathrm{Xu}$ M, Qiao Y, Zheng S. Differentiation and migration of bone marrow mesenchymal stem cells transplanted through the spleen in rats with portal hypertension. PLoS One. 2013;8:e83523.

23. Bradley H, Shaw CS, Bendtsen C, Worthington PL, Wilson OJ, Strauss JA, Wallis GA, Turner AM, Wagenmakers AJ. Visualization and quantitation of glut4 translocation in human skeletal muscle following glucose ingestion and exercise. Physiol Rep. 2015;3(5):e12375.

24. YY W, Singer CA, Buxton IL. Variants of stretch-activated two-pore potassium channel trek-1 associated with preterm labor in humans. Biol Reprod. 2012;87:96

25. ZH Y, JR X, Wang YX, GN X, ZP X, Yang K, DZ W, Cui YY, Chen HZ. Targeted inhibition of kca3.1 channel attenuates airway inflammation and remodeling in allergic asthma. Am J Respir Cell Mol Biol. 2013;48:685-93.

26. Schneider CA, Rasband WS, Eliceiri KW. Nih image to imagej: 25 years of image analysis. Nat Methods. 2012;9:671-5.

27. Gopalakrishnan SM, Moreland RB, Kofron JL, Helfrich RJ, Gubbins E, McGowen J, Masters JN, Donnelly-Roberts D, Brioni JD, Burns DJ, Warrior UA. cell-based microarrayed compound screening format for identifying agonists of g-protein-coupled receptors. Anal Biochem. 2003;321:192-201.

28. Iglesias J, Morales L, Barreto GE. Metabolic and inflammatory adaptation of reactive astrocytes: Role of ppars. Mol Neurobiol. 2017;54:2518-38.

29. Wang LP, Cheung G, Kronenberg G, Gertz K, Ji S, Kempermann G, Endres M, Kettenmann $\mathrm{H}$. Mild brain ischemia induces unique physiological properties in striatal astrocytes. Glia. 2008:56:925-34.

30. Lallet-Daher H, Roudbaraki M, Bavencoffe A, Mariot P, Gackiere F, Bidaux G, Urbain R, Gosset P, Delcourt P, Fleurisse L, Slomianny C, Dewailly E, Mauroy B, Bonnal JL, Skryma R, Prevarskaya N. Intermediate-conductance ca2+ -activated k+ channels (ikca1) regulate human prostate cancer cell proliferation through a close control of calcium entry. Oncogene. 2009;28: 1792-806.

31. Devor DC, Singh AK, Frizzell RA, Bridges RJ. Modulation of $\mathrm{cl}$ - secretion by benzimidazolones. I. Direct activation of a ca(2+)-dependent k+ channel. Am J Phys. 1996;271:L775-84.

32. Wandall-Frostholm C, Dalsgaard T, Bajoriunas V, Olivan-Viguera A, Sadda V, Beck L, Mogensen S, Stankevicius E, Simonsen U, Kohler R. Genetic deficit of kca 3.1 channels protects against pulmonary circulatory collapse induced by trpv4 channel activation. Br J Pharmacol. 2015;172:4493-505.

33. Sonkusare SK, Bonev AD, Ledoux J, Liedtke W, Kotlikoff MI, Heppner TJ, HillEubanks DC, Nelson MT. Elementary ca2+ signals through endothelial trpv4 channels regulate vascular function. Science. 2012;336:597-601.

34. Chen YJ, Nguyen HM, Maezawa I, Grossinger EM, Garing AL, Kohler R, Jin LW, Wulff H. The potassium channel kca3.1 constitutes a pharmacological target for neuroinflammation associated with ischemia/reperfusion stroke. J Cerebral Blood Flow Metab. 2016;36:2146-61.

35. Gueguinou M, Chantome A, Fromont G, Bougnoux P, Vandier C, PotierCartereau M. Kca and $\mathrm{ca}(2+)$ channels: The complex thought. Biochim Biophys Acta. 2014;1843:2322-33.

36. Gueguinou M, Gambade A, Felix R, Chantome A, Fourbon Y, Bougnoux P, Weber G, Potier-Cartereau M, Vandier C. Lipid rafts, kca/clca/ca2+ channel complexes and egfr signaling: Novel targets to reduce tumor development by lipids? Biochim Biophys Acta. 2015;1848:2603-20.

37. Li Y, Hu H, Tian JB, Zhu MX, O'Neil RG. Dynamic coupling between trpv4 and ca2+-activated $s k 1 / 3$ and ik1 k+ channels plays a critical role in regulating the $\mathrm{k+-}$-secretory bk channel in kidney collecting duct cells. Am J Physiol Renal Physiol. 2017;312:F1081-9.

38. Qian X, Francis M, Kohler R, Solodushko V, Lin M, Taylor MS. Positive feedback regulation of agonist-stimulated endothelial ca2+ dynamics by kca3.1 channels in mouse mesenteric arteries. Arterioscler Thromb Vasc Biol. 2014;34:127-35

39. Simonsen U, Wandall-Frostholm C, Olivan-Viguera A, Kohler R. Emerging roles of calcium-activated k channels and trpv4 channels in lung oedema and pulmonary circulatory collapse. Acta Physiol. 2017;219:176-87. 
40. Ryskamp DA, Witkovsky P, Barabas P, Huang W, Koehler C, Akimov NP, Lee SH, Chauhan S, Xing W, Renteria RC, Liedtke W, Krizaj D. The polymodal ion channel transient receptor potential vanilloid 4 modulates calcium flux, spiking rate, and apoptosis of mouse retinal ganglion cells. J Neurosci. 2011; 31:7089-101.

41. Shi M, Du F, Liu Y, Li L, Cai J, Zhang GF, XF X, Lin T, Cheng HR, Liu XD, Xiong LZ, Zhao G. Glial cell-expressed mechanosensitive channel trpv4 mediates infrasound-induced neuronal impairment. Acta Neuropathol. 2013; 126:725-39.

42. Benfenati V, Caprini M, Dovizio M, Mylonakou MN, Ferroni S, Ottersen OP, Amiry-Moghaddam M. An aquaporin-4/transient receptor potential vanilloid 4 (aqp4/trpv4) complex is essential for cell-volume control in astrocytes. Proc Natl Acad Sci U S A. 2011;108:2563-8.

43. Isogai A, Lee K, Mitsui R, Hashitani H. Functional coupling of trpv4 channels and bk channels in regulating spontaneous contractions of the guinea pig urinary bladder. Pflugers Archiv. 2016;468:1573-85.

44. Parikh J, Kapela A, Tsoukias NM. Stochastic model of endothelial trpv4 calcium sparklets: Effect of bursting and cooperativity on edh. Biophys $\mathrm{J}$. 2015;108:1566-76.

45. Feetham CH, Nunn N, Lewis R, Dart C, Barrett-Jolley R. Trpv4 and k(ca) ion channels functionally couple as osmosensors in the paraventricular nucleus. Br J Pharmacol. 2015:172:1753-68.

46. Sofroniew MV. Multiple roles for astrocytes as effectors of cytokines and inflammatory mediators. Neuroscientist. 2014;20:160-72.

47. Liddelow SA, Guttenplan KA, Clarke LE, Bennett FC, Bohlen CJ, Schirmer L, Bennett ML, Munch AE, Chung WS, Peterson TC, Wilton DK, Frouin A, Napier BA, Panicker N, Kumar M, Buckwalter MS, Rowitch DH, Dawson VL, Dawson TM, Stevens B, Barres BA. Neurotoxic reactive astrocytes are induced by activated microglia. Nature. 2017;541:481-7.

48. Ferreira R, Lively S, Schlichter LC. II-4 type 1 receptor signaling up-regulates kcnn4 expression, and increases the kca3.1 current and its contribution to migration of alternative-activated microglia. Front Cell Neurosci. 2014;8:183.

49. Kaushal V, Koeberle PD, Wang Y, Schlichter LC. The ca2+-activated k+ channel kcnn4/kca3.1 contributes to microglia activation and nitric oxidedependent neurodegeneration. J Neurosci. 2007;27:234-44.

\section{Submit your next manuscript to BioMed Central and we will help you at every step:}

- We accept pre-submission inquiries

- Our selector tool helps you to find the most relevant journal

- We provide round the clock customer support

- Convenient online submission

- Thorough peer review

- Inclusion in PubMed and all major indexing services

- Maximum visibility for your research

Submit your manuscript at www.biomedcentral.com/submit

) Biomed Central 